\title{
Is It Necessary to Reduce Thoracolumbar Compression Fractures with Intermediate Screws in the Fractured Vertebra?
}

\section{ZeJun Xing ( $\sim 13810608620 @ 163 . c o m)$}

Shanxi Bethune Hospital https://orcid.org/0000-0001-9149-5229

\section{Shuai Hao}

Shanxi Bethune Hospital

\section{XiaoFei Wu}

Shanxi Bethune Hospital

\section{Research article}

Keywords: Thoracolumbar fracture, Percutaneous pedicle screw, Intermediate screw, Minimally invasive surgery

Posted Date: June 2nd, 2021

DOl: https://doi.org/10.21203/rs.3.rs-542387/v1

License: (c) (1) This work is licensed under a Creative Commons Attribution 4.0 International License. Read Full License 


\section{Abstract}

\section{Purpose}

To compare the efficacy and safety of percutaneous short-segment pedicle screws fixation (PPSF) with or without intermediate screws (IS) for the treatment of thoracolumbar compression fractures.

\section{Methods}

From January 2016 to March 2019, a retrospective study of 38 patients with thoracolumbar compression fractures conducted. The patients were divided into a 4-screw group (without IS) and a 6-screw group (with IS) according to whether pedicle screws were placed in the fractured vertebrae. Combined positional reduction effects with the technique of pre-contoured lordotic rods were used to reduce the fracture by lengthening the anterior column of the fractured vertebrae. The posterior structure of the fractured vertebrae was undertaken as the fulcrum point for both groups. The operation time, intra-operative blood loss, visual analogue scale (VAS), anterior vertebral body height (AVBH), segment kyphosis 『SKखbefore and after operation and complications were recorded.

Results

Although the operation time and blood loss in the 6-screw group were higher than in the 4-screw group, difference was not significant (P囚0.05). There was no significant difference in VAS, AVBH and SK between the two groups $(P \llbracket 0.05)$. Nevertheless, these results were significant differences between the preoperative and the immediate postoperative, between preoperative and follow-up groups $(P<0.001)$. No neurologic injury was observed in either groups.

\section{Conclusions}

In the treatment of thoracolumbar compression fractures, percutaneous short-segment pedicle screws fixation without intermediate screws in the 4-screw construct may obtain the same clinical effect as that in the 6-screw construct.

\section{Introduction}

The goal of treating thoracolumbar fractures is to restore spinal stability, preserve neurologic function and allow the patient to resume normal activities as soon as possible. Controversy persists over the choice of operative versus nonoperative treatment in some fracture types, especially in patients without severe neurological symptoms. The advantages of conservative treatment are to avoiding surgery, reducing the risk of complications and reducing the cost of surgery [1]. However, some studies reported the failure of conservative treatment in about $20 \%$ of these patients [2]. Posterior short-segment fixation without direct spinal decompression is the most commonly used procedure to reduce vertebral fracture and decompress the spinal canal indirectly [3]. A posterior short-segment 4-screw construct with pedicle 
but often causes fractures of internal fixation due to osteoporosis and correction loss [4]. Long-segment internal fixation (LSIF) and short-segment with intermediate screws (IS) in the fracture level have been used in place of the 4-screw construct, both of which achieved satisfactory clinical efficacy. LSIF is unnecessarily extensive and decreases the number of motion segments. Therefore, the posterior shortsegment fixation combined with two intermediate screws (6-screw construct) is a better choice which not only significantly increases spinal stability and provides stronger fixation ,but also reduces the stress on the non-fractured vertebra $[5,6]$.

Notwithstanding, the 6-screw construct inevitably increases the cost and time of operation. The development of minimally invasive percutaneous posterior pedicle screw implication has made recovery easier and faster by preserving paravertebral muscle tissue, avoiding injury to the facet joint capsule, and reducing bleeding, postoperative pain, operative time, and the length of hospitalization, which make rehabilitation easier and faster $[7,8]$. Although the biomechanical properties of traditional and modern pedicle screw systems have not yet been studied, we believe that modern internal fixation is an easier operation and is more durable. As such, we performed this study to explore whether percutaneous shortsegment pedicle screws without IS (4-screw construct) would provide enough force to reduce thoracolumbar fracture, maintain stability and achieve the same clinical results compared with the 6screw construct.

\section{Materials And Methods}

\section{Study Population}

Our hospital Ethics committee approved this retrospective study. Thirty-eight consecutive patients were treated for thoracolumbar fractures using minimally invasive percutaneous pedicle screws combined with pre-contoured rods from January 2016 to March 2019. The cohort was composed of 27 males and 11 females. The average age at surgery was 35.9 (21-59) years. The fractured levels were located between T12 and L2, all of which were classified as Type A according to the AO/ Magerl classification [9]. The patients were divided into a 4-screw group $(n=16)$ and a 6-screw group $(n=22)$ according to the number of intermediate screws placed in the fractured vertebra. All patients were operated within 1 week after the injury. Clinical and radiographic follow-up were performed preoperatively and postoperatively,at 1 week, 6 months, 12 months.

Surgical procedures

Under general anesthesia, the patient was placed on a cushion in the prone position, with both shoulders and the superior iliac spine supported by gel pads to reduce the intra-abdominal pressure, and hyperextending the spine to achieve postural reduction. Firstly, four mono-axial pedicle screws were inserted to bilateral pedicles of the adjacent vertebrae in the 4-screw group after determination of the fracture level. Poly-axial pedicle screws were used as intermediate screws to place the fractured vertebrae body parallel to the endplate of the adjacent normal vertebrae in a convergent direction in the 6-screw Loading [MathJax]/jax/output/CommonHTML/jax.js axial pedicle screws are usually slightly shorter than that of 
the mono-axial screws. All screws were inserted percutaneously and guided by navigation. Secondly, suitable pre-contoured lordotic rods were inserted via intramuscular spaces from the rostral to the caudal level. Thirdly, the set screws were locked alternatively from the caudal to the rostral on both sides to reduce the fractured vertebrae. Intraoperative fluoroscopy confirmed the reduction effect, and at least the anterior vertebra height was restored to greater than $90 \%$, otherwise a rod with greater curvature was needed (Fig. 1.).

Follow-up

For all 38 patients, procedures were checked by lateral-view radiographs. The rehabilitation program was started the day after surgery. Bracing was prescribed for patients during 12 weeks after surgery. All patients were followed up clinically and radiographically at 1 week, 6 months, and 12 months or more postoperatively. Visual analog scale (VAS) was used to evaluate the patient's back pain. Anteroposterior and lateral X-ray were done in the prone position in preoperative because of spine fracture, while it was done in standing position in postoperatively and at the follow up. Implants was removed 1 to 2 years after surgery. Segmental kyphosis (SK) was measured using the subtended angle between the adjacent intact endplates on lateral radiographs. The anterior height of the injured vertebra and adjacent normal vertebrae were measured. The anterior vertebra body height (AVBH) percentage was calculated as previously described [10].

\section{Statistical analysis}

Cmparative t-tests and repeated measures analysis of variance (ANOVA) were performed to analyze the variables using SPSS version.-21.0 (IBM Co., Armonk, NY, USA). The significance level of was set at $P$ \0.05 for all statistical tests.

\section{Results}

All patients were followed up for 12 to 30 months, with an average of 15.2 months. There was no significant difference between the two groups in operation time and intraoperative blood loss $(P \otimes 0.05)$ (Table 1). There were significant differences in the VAS value between the preoperative and the immediate postoperative measurements, between preoperative and follow-up groups $(P<0.001)$. However there was no significant difference in different follow-up time (P凶0.05) (Table 2). Both AVBH and SK showed a similar trend. Nevertheless, there was a partial loss of the final corrective effect compared with immediate postoperative, but no statistically significant difference was observed (Table 2). No neurologic injury was observed in both groups. (Fig. 2 and Fig. 3) 
Table 1

Comparison of demographic and surgical data between the 6-screw and 4-screw group.

\begin{tabular}{|c|c|c|c|}
\hline Variables & 6-screw & 4-screw & $P$ \\
\hline Age (years) & $42.0 \pm 8.2$ & $34.3 \pm 9.1$ & 0.529 \\
\hline Gender (M/F) & $16 / 6$ & $11 / 5$ & 1.000 \\
\hline \multicolumn{4}{|l|}{ AO Type } \\
\hline A2 & 7 & 4 & \multirow[t]{2}{*}{$\otimes 0.05$} \\
\hline A3 & 15 & 12 & \\
\hline \multicolumn{4}{|l|}{ Injury level } \\
\hline T12 & 8 & 6 & \multirow[t]{3}{*}{ 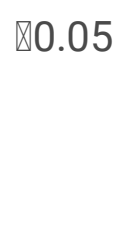 } \\
\hline L1 & 9 & 5 & \\
\hline L2 & 5 & 5 & \\
\hline Operative time(min) & $44.7 \pm 12.6$ & $39.3 \pm 11.9$ & 0.504 \\
\hline Blood loss (ml) & $56.8 \pm 13.3$ & $48.4 \pm 11.0$ & 0.061 \\
\hline
\end{tabular}


Table 2

Comparison of clinical and radiographic data between the 6-screws and 4-screws group.

\begin{tabular}{|c|c|c|c|c|c|c|c|c|}
\hline \multirow[t]{2}{*}{ Variables } & \multirow[t]{2}{*}{ Groups } & \multirow[t]{2}{*}{ Preoperative } & \multirow{2}{*}{$\begin{array}{l}1 \mathrm{w} \\
\text { follow- } \\
\text { up }\end{array}$} & \multirow{2}{*}{$\begin{array}{l}6 \mathrm{~m} \\
\text { follow- } \\
\text { up }\end{array}$} & \multirow{2}{*}{$\begin{array}{l}12 \mathrm{~m} \\
\text { follow- } \\
\text { up }\end{array}$} & \multicolumn{3}{|l|}{$P$} \\
\hline & & & & & & time $\Delta$ & group $\nabla$ & TXG* \\
\hline \multirow[t]{2}{*}{ VAS } & $\begin{array}{l}\text { 6- } \\
\text { screws }\end{array}$ & $6.7 \pm 1.5$ & $\begin{array}{l}2.3 \pm \\
0.9\end{array}$ & $\begin{array}{l}1.1 \pm \\
0.3\end{array}$ & $0.9 \pm 0.5$ & \multirow[t]{2}{*}{$\begin{array}{l}< \\
0.001\end{array}$} & \multirow[t]{2}{*}{0.3067} & \multirow[t]{2}{*}{0.0841} \\
\hline & $\begin{array}{l}4- \\
\text { screws }\end{array}$ & $6.1 \pm 1.7$ & $\begin{array}{l}2.1 \pm \\
0.8\end{array}$ & $\begin{array}{l}1.2 \pm \\
0.6\end{array}$ & $1.0 \pm 0.6$ & & & \\
\hline \multirow[t]{2}{*}{$\begin{array}{l}\text { AVBH } \\
(\%)\end{array}$} & $\begin{array}{l}\text { 6- } \\
\text { screws }\end{array}$ & $59.5 \pm 13.6$ & $\begin{array}{l}90.6 \pm \\
7.7\end{array}$ & $\begin{array}{l}89.3 \pm \\
8.3\end{array}$ & $\begin{array}{l}88.4 \pm \\
7.9\end{array}$ & \multirow[t]{2}{*}{$<.001$} & \multirow[t]{2}{*}{0.164} & \multirow[t]{2}{*}{0.996} \\
\hline & $\begin{array}{l}\text { 4- } \\
\text { screws }\end{array}$ & $60.1 \pm 12.5$ & $\begin{array}{l}89.3 \pm \\
8.9\end{array}$ & $\begin{array}{l}88.4 \pm \\
9.1\end{array}$ & $\begin{array}{l}86.5 \pm \\
8.7\end{array}$ & & & \\
\hline \multirow[t]{2}{*}{$\operatorname{SK}\left({ }^{0}\right)$} & $\begin{array}{l}\text { 6- } \\
\text { screws }\end{array}$ & $15.6 \pm 4.1$ & $\begin{array}{l}3.0 \pm \\
1.8\end{array}$ & $\begin{array}{l}5.8 \pm \\
1.9\end{array}$ & $5.9 \pm 1.8$ & \multirow[t]{2}{*}{$\begin{array}{l}<.001 \\
0.00\end{array}$} & \multirow[t]{2}{*}{0.823} & \multirow[t]{2}{*}{0.715} \\
\hline & $\begin{array}{l}\text { 4- } \\
\text { screws }\end{array}$ & $16.2 \pm 5.1$ & $\begin{array}{l}3.1 \pm \\
1.4\end{array}$ & $\begin{array}{l}5.2 \pm \\
2.3\end{array}$ & $5.6 \pm 2.1$ & & & \\
\hline
\end{tabular}

\section{Discussion}

The incidence of thoracolumbar spinal injuries has been increasing due to motor vehicle accidents and falls from a height $[11,12]$. Although surgery is frequently indicated with a TLICS classification of 5 points or above [13], especially for unstable Type A, Type B and Type C, the choice of the treatment for stable Type A remain controversial. Some studies reported operative treatment provided no major longterm advantage compared with nonoperative treatment [14]. However, Hitchon PW et al [15] reported that 18 of 68 patients with a TLICS score of 2 required early operative intervention rather than nonoperative treatment due to pain. The most common treatment for thoracolumbar fracture is short-segment internal fixation via posterior approach. The 6-screw construct with IS in the fractured vertebra generates a segmental construct, which demonstrated improved biomechanical stability compared with a nonsegmental construct [16]. Dick et al [17] conducted a study which indicated that the use of intermediate pedicles increased axial, flexional, and torsional stiffness by varying degrees when compared with the 4-screw construct. Wang et al [18] also noted that the addition of IS at the level of a burst fracture significantly increases the stability of a short-segment pedicle fixation. However, even though 6-screw constructs are better than 4-screw constructs in biomechanical testing, whether 4-screw constructs are enough to meet the purpose of reduction and maintaining stability until fracture healing for most stable Type A fractures is unclear. In our study, posterior percutaneous short-segment with the 4- 
screw construct method was a reliable and satisfactory treatment for the stable type A thoracolumbar compression fracture.

Despite the use of traditional posterior open surgical techniques to correct deformity, stabilize the spine, and maintain neurological function, these techniques including short-segment fixation with or without IS, require extensive exposure, which can be associated with significant high intra-operative blood loss, prolonged surgery time, increased infection rates, and paraspinal muscle denervation or injury $[19,20]$. With the development of surgical technology and internal fixation materials, the efficacy of percutaneous pedicle screw fixation for traumatic spine fractures have been reported. Compared with open surgical technique, percutaneous pedicle screw is associated with less paraspinal muscle damage, less blood loss, shorter hospital stays, and improved peri-operative pain scores [20,21]. Another important feature is that modern pedicle screw system have been modified to reduce pedicle screw fracture rates and to facilitate application of the connecting rod without putting excessive stress on the construct [22, 23].

In our clinical practice, we sought to use as few and simple steps as possible to reduce the fracture. The first important step for reducing the fractured vertebra is postural reduction, which is easily performed through the lordotic prone position. Secondly, the use of mono-axial screws near the fractured vertebra may be helpful when reducing the fracture by providing a $90^{\circ}$ connection between the screw and the lordotic rod, thus lengthening the anterior column. In this step, ligamentotaxis of the anterior longitudinal ligament ( $(\mathrm{LL})$ ) and the posterior longitudinal ligament $(\mathrm{PLL})$ plays an important role in correcting the collapsed vertebral bodies and segmental kyphosis. As the ligamentotaxis of the ALL and PLL are straightened, the length of the spine is adjusted. Thirdly, the rods are pre-contoured with the use of a French rod bender according to the sagittal index angle on the lateral x-ray [24]. The rod was then inserted from the proximal to the caudal side through the paraspinal muscle gap approach to reduce the risk of rod entry into the spinal canal. Reduction of the fracture is visible when the nut is tightened. If the reduction is not satisfactory, the rod is bent again until the reduction reaches at least $90 \%$ according to the intraoperative fluoroscopy. In this step, we observed that the titanium rods gradually lose their original curved shape to become nearly straight and, at the same time, the fractured vertebra was reduced (Fig. 1). The operation was simple and easy to perform, without the need for special equipment such as in the "in situ contouring" technique [25].

From our study, it can be seen that both internal fixation devices can achieve satisfactory results. First, in this procedure, the posterior structure of the fracture vertebrae, which in contact with rods in the 4-screw construct, is undertaken the fulcrum point, similar to the intermediate screws in the 6-screw construct. This allows for a 3-point reduction maneuver analogous to that used for reduction of long bone fractures. Secondly, the deformed titanium rod not only serves the purpose of correction and reduction, but also has the ability to maintain the reduction through elastic retraction. Finally, the most important reason is that minimally invasive surgery does not damage the paravertebral muscles, which plays an important role in reducing pain and maintaining spinal stability.

\section{Limitations}

Loading [MathJax]/jax/output/CommonHTML/jax.js 
The limitations of this study should be acknowledged. Firstly, the present study was conducted as a retrospective study. Due to the retrospective design, the two groups of patients with fractured vertebrae were in different positions, which may have led to some deviation. Secondly, both groups consisted of small sample size. Thirdly, we only included stable fractured vertebra.

In conclusion, the results of this study suggested that both the 4-screw construct and the 6-screw construct could achieve satisfactory surgical outcomes to treat thoracolumbar compression fractures. Thus, we recommend posterior percutaneous short-segment 4-screw fixation for thoracolumbar compression fractures.

\section{Declarations}

\section{Acknowledgements}

The first three authors completed data collection, data statistics and article writing. This study was approved by the Shanxi Bethune Hospital Instiutional Review Board. The authors thank AiMi Academic Services (www.aimieditor.com) for English language editing and review services.

\section{Conflict of interest}

The authors declare that they have no conflict of interest.

\section{References}

1. Wood KB, Buttermann GR, Phukan R et al (2015) Operative compared with nonoperative treatment of a thoracolumbar burst fracture without neurological deficit: a prospective randomized study with follow-up at sixteen to twenty-two years. J Bone Joint Surg Am 97(1):3-9

2. Shen J, Xu L, Zhang B et al (2015) Risk factors for the failure of spinal burst fractures treated conservatively according to the thoracolumbar injury classification and severity score (TLICS): a retrospective cohort trial. PloS One 10 (8): e0135735

3. Mohanty SP, Bhat SN, Ishwara-Keerthi C (2011) The effect of posterior instrumentation of the spine on canal dimensions and neurological recovery in thoracolumbar and lumbar burst fractures. Musculoskelet Surg 95(2):101-106

4. McLain RF Sparling E, Benson DR (1993) Early failure of short-segment pedicle instrumentation for thoracolumbar fractures. A preliminary report. J Bone Joint Surg Am 75(2):162-167

5. Norton RP, Milne EL, Kaimrajh DN et al (2014) Biomechanical analysis of four- versus six-screw constructs for short-segment pedicle screw and rod instrumentation of unstable thoracolumbar fractures. Spine J 14(8):1734-1739

6. Baaj AA, Reyes PM, Yaqoobi AS et al (2011) Biomechanical advantage of the index-level pedicle screw in unstable thoracolumbar junction fractures. J Neurosurg Spine 14(2):192-197 
7. Rampersaud YR, Annand N, Dekutoski MB (2006) Use of minimally invasive surgical techniques in the management of thoracolumbar trauma: current concepts. Spine (Phila Pa 1976) 31(11 suppl): S96-102

8. Smith JS, Ogden AT, Fessler RG (2008) Minimally invasive posterior thoracic fusion. Neurosurg Focus 25(2): E9

9. Magerl F, Aebi M, Gertzbein SD et al (1994) A comprehensive classification of thoracic and lumbar injuries. Eur Spine J 3(4):184-201

10. Mumford J, Weinstein JN, Spratt KF et al (1993) Thoracolumbar burst fractures. The clinical efficacy and outcome of nonoperative management. Spine (Phila Pa 1976) 18(8):955-970

11. Doud AN, Weaver AA, Talton JW et al (2015) Has the incidence of thoracolumbar spine injuries increased in the United States from 1998 to 2011? Clin Orthop Relat Res 473(1):297-304

12. Liu P, Yao Y, Liu MY et al (2012) Spinal trauma in mainland China from 2001 to 2007: an epidemiological study based on a nationwide database. Spine (Phila Pa 1976) 37(15):1310-1315

13. Vaccaro AR, Jr L RA, John H R et al (2005) A new classification of thoracolumbar injuries: the importance of injury morphology, the integrity of the posterior ligamentous complex, and neurologic status. Spine (Phila Pa 1976) 30(20):2325-2333

14. Wood K, Buttermann G, Mehbod A et al (2003) Operative compared with nonoperative treatment of a thoracolumbar burst fracture without neurological deficit: a prospective, randomized study. J Bone Joint Surg Am 85(5):773-781

15. Hitchon PW, Abode-lyamah K, Dahdaleh N S et al (2016) Nonoperative management in neurologically intact thoracolumbar burst fractures: Clinical and radiographic outcomes. Spine (Phila Pa 1976) 41(6):483-489

16. Mahar A, Kim C, Wedemeyer M et al (2007) Short segment fixation of lumbar burst fractures using pedicle fixation at the level of the fracture. Spine (Phila Pa 1976) 32(14):1503-1507

17. Dick JC, Jones MP, Zdeblick TA et al (1994) A biomechanical comparison evaluating the use of intermediate screws and cross-linkage in lumbar pedicle fixation. J Spinal Disord 7(5):402-407

18. Wang H, Li C , Liu T et al $₫ 2012 \triangle$ Biomechanical efficacy of monoaxial or polyaxial pedicle screw and additional screw insertion at the level of fracture, in lumbar burst fracture: An experimental study. Indian J Orthop 46(4):395-401

19. Foley KT, Gupta SK, Justis JR et al (2001) Percutaneous pedicle screw fixation of the lumbar spine. Neurosurg Focus 10®4『: E10

20. Palmisani M, Gasbarrini A, Brodano GB et al. (2009) Minimally invasive percutaneous fixation in the treatment of thoracic and lumbar spine fractures. Eur Spine J 18 Suppl 1(Suppl 1):71-74

21. Wild MH, Glees M, Plieschnegger C et al (2007) Five-year follow-up examination after purely minimally invasive posterior stabilization of thoracolumbar fractures: a comparison of minimally invasive percutaneously and conventionally open treated patients. Arch Orthop Trauma Surg 127(5): 335- 343 
22. McKinley TO, McLain RF, Yerby SA et al (1999). Characteristics of pedicle screw loading. Effect of surgical technique on intravertebral and intrapedicular bending moments. Spine (Phila Pa 1976) 24(1):18-24, discussion 25

23. Fogel GR, Reitman CA, Liu W et al (2003) Physical characteristics of polyaxial-headed pedicle screws and biomechanical comparison of load with their failure. Spine (Phila Pa 1976) 28(5):470-473

24. Farcy JP, Weidenbaum M, Glassman SD (1990) Sagittal index in management of thoracolumbar burst fractures. Spine (Phila Pa 1976)15(9):958-965

25. Steib JP, Aoui M, Mitulescu A et al (2006) Thoracolumbar fractures surgically treated by "in situ contouring". Eur Spine J 15(12):1823-1832

\section{Figures}

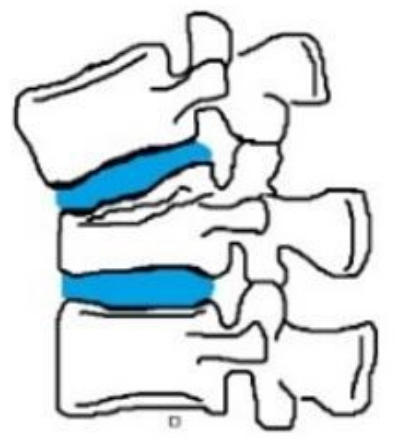

A

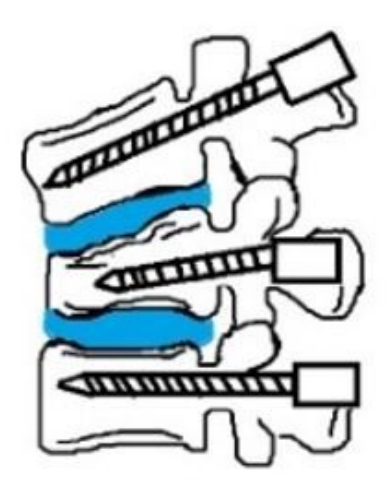

B

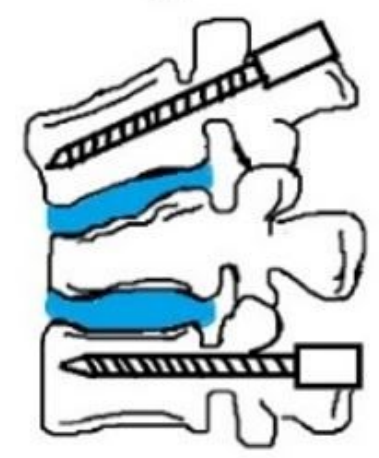

B "

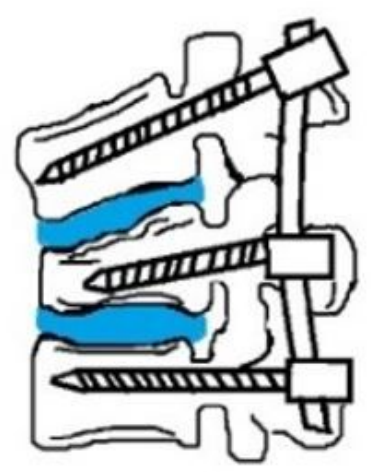

$\mathrm{C}$

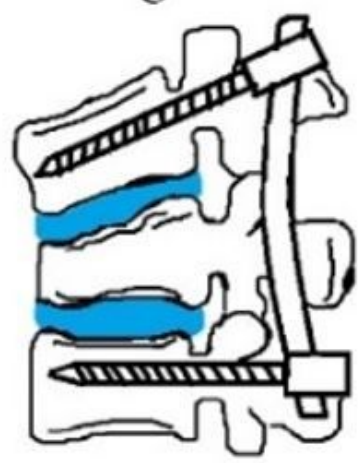

C"

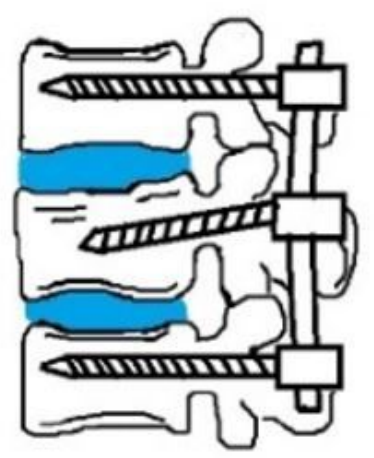

$\mathrm{D}$



D "

Figure 1

Schematic diagram of reduction mechanism. (Top: 6-screw group; Bottom: 4-screw group) 



\section{Figure 2}

A 48-year-old male with a L1 compression fracture caused by falling. Preoperatively, the patient had relatively severe pain and no neurologic injury. $A V B H>30 \%, S K=-100(A)$; Intraoperative navigation , placing the pedicle screw and reduction (B, C, D); Post-operation, AVBH was restored, and the $S K=00(E)$; Postoperative incision general image $(F)$; Image before and after removing internal fixation $(G, H)$. 

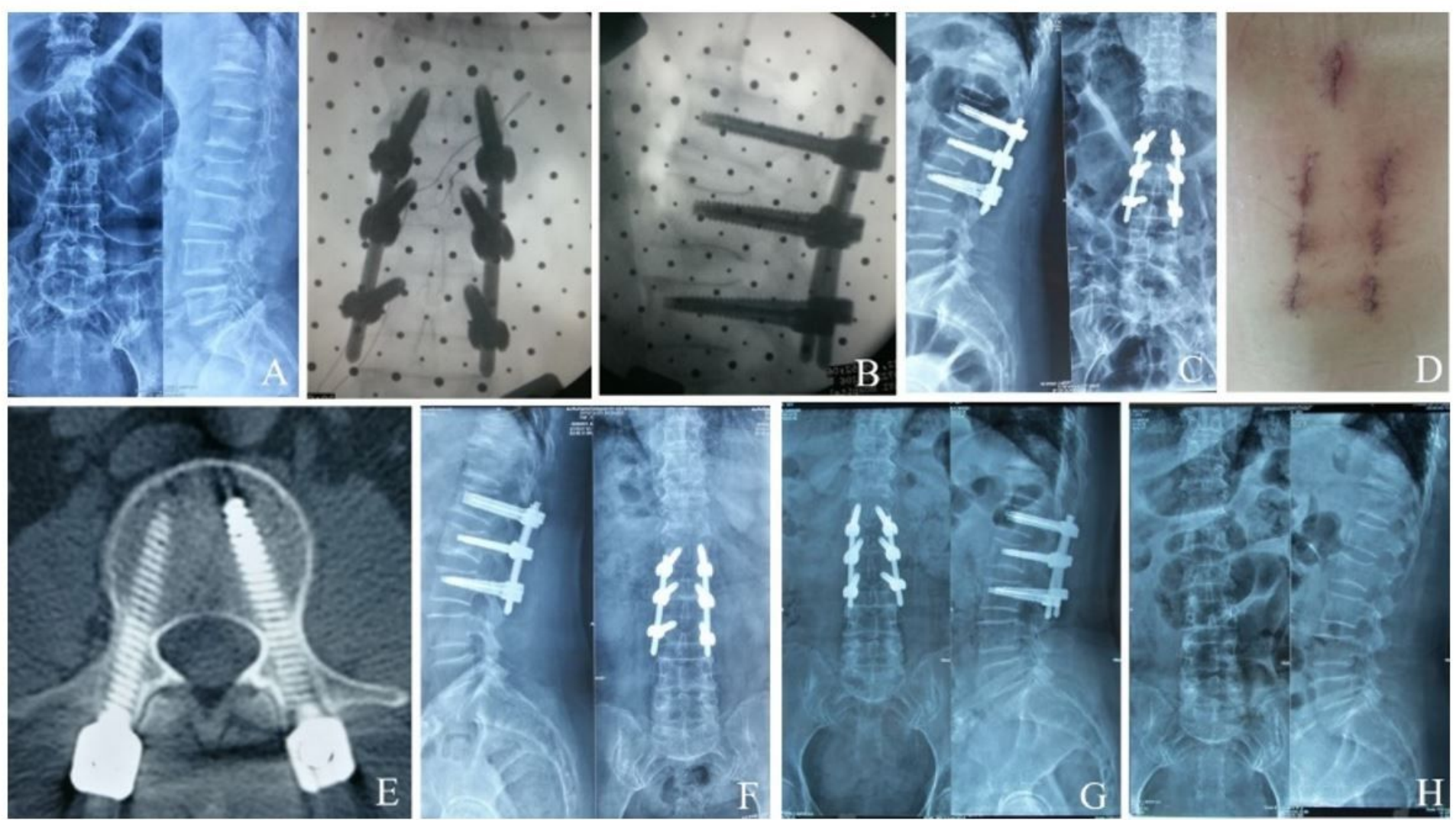

Figure 3

A 53-year-old female with a L2 compression fracture due to motor vehicle accident. Preoperatively, the patient had relatively severe pain and no neurologic injury. AVBH $>30 \%, S K=-120(A)$; Intraoperative navigation , placing the pedicle screw and reduction (B); Post-operation, AVBH was restored, and the $S K=00(C)$; Postoperative incision general image (D); Image before and after removing internal fixation ( $E$, $F, G, H)$.

\section{Supplementary Files}

This is a list of supplementary files associated with this preprint. Click to download.

- renamed89e41.pdf 